\title{
Pellet Heat Transfer Coefficients in Packed Beds: Global and Local Values
}

\author{
Ruud J. Wijngaarden and K. Roel Westerterp*
}

Pellet heat transfer coefficients in a packed bed have been obtained, both for specific individual pellets and for the entire bed. They are referred to as local and global values, respectively. It appears that the local values are scattered around the global value. This is due to the heat transfer coefficient of individual pellets being statistically distributed, as a result of the randomness of the packing. At low Reynolds numbers, both global and local values fall well below $\mathrm{Nu}=2$, which is the lower limit for a single sphere in absence of convection. In the literature, this behaviour has been attributed i.a. to axial dispersion and fluid maldistribution. However, these phenomena cannot explain why the same behaviour is observed in slurries. The fact that the local values fall below $\mathrm{Nu}=2$ would suggest that neither of these explanations is valid for packed beds.

\section{Introduction}

Several results have been reported on the heat transfer between a pellet and gas, see e.g. Ranz [1]. More recently Gnielinski $[2,3]$ put forward correlations which can be used for high particle Reynolds numbers and which cover a wide range of published data. For low particle Reynolds numbers, the Nusselt number decreases rapidly to zero. In this range, the correlations of Ranz [17] and Gnielinski $[2,3]$ fail to provide a satisfactory description. Kunii and Suzuki [4], Gunn and de Souza [5], Nelson and Galloway [6] and Martin [7] attempted to give a mathematical explanation as to why the Nusselt numbers drop well below the limiting value of two which holds for a single sphere without convection.

The channelling idea has been elaborated by Kunii and Suzuki [4] and by Martin [7]. According to these workers, the $\mathrm{Nu}$ value in a packed bed falls below 2 , not on account of the $\mathrm{Nu}$ numbers of individual pellets dropping below 2 but because of maldistribution of the gas flowing through the macropores in the bed as argued by Kunii and Suzuki or the gas prefers to flow via the high porosity area near the wall as suggested by Martin.

Gunn and de Souza [5] explained why Nu drops below 2 at low velocities by the fact that if the axial dispersion of heat, which then becomes very significant, is neglected, it will be incorporated in the value of $\alpha_{\mathrm{p}}$. This indeed will be the case if we use a global, i.e. bed scale, model for the packed bed because axial dispersion will produce flatter axial temperature profiles. In addition, a reduction in $\alpha_{\mathrm{p}}$, all other conditions remaining the same, will flatten the axial profile because a longer bed is needed to transfer the same amount of heat from gas to solids. This process largely determines

\footnotetext{
* Dr. R. J. Wijngaarden (Present address: Koninklijke/Shell-Laboratorium, Amsterdam, P.O. Box 3003, 1003 AA Amsterdam, The Netherlands) and Prof. Dr. K. R. Westerterp (Author to whom correspondence should be addressed), Chemical Reaction Engineering Laboratories, Department of Chemical Engineering, Twente University, P.O. Box 217, 7500 AE Enschede, The Netherlands.
}

the axial profile in the bed. Thus, at an unallowable neglect of axial dispersion, and on obtaining the values of $\alpha_{\mathrm{p}}$ by fitting temperature profiles, the dispersion will yield an apparent decrease in $\alpha_{\mathrm{p}}$.

Nelson and Galloway [6] provided the following explanation. On assuming the contact between the gas and the pellet to last for $d_{\mathrm{p}} / v_{0}$, and inserting this time into a penetration model, which describes the pellet as surrounded by an isotropic medium, i.e. with the same thermal diffusion coefficient all-over, and stipulates that there is hardly any heat transport by convection, they found that, at low velocities, $\alpha_{\mathrm{p}}$ must be proportional to the velocity and approaches zero in the absence of flow.

Yagi et al. [8] measured the particle to liquid mass transfer coefficients in slurries and observed that, also in this case, the Sherwood number can fall below two. Since, in stirred slurries, channelling is very unlikely and axial dispersion cannot provide a suitable explanation, this suggests that the hypotheses of Kunii and Suzuki [4], Martin [7] and Gunn and de Souza [5] are less plausible. Agreement with the model of Nelson and Galloway [6] was satisfactory.

To verify the hypotheses of Kunii and Suzuki [4], Martin [7] and Gunn and de Souza [5] for packed beds, one could measure local, i.e. pellet scale, $\alpha_{\mathrm{p}}$ values, since, according to these theories, they should not fall below $\mathrm{Nu}=2$. Attempts to accomplish this are discussed in the following.

\section{Measurement Techniques}

\subsection{Global Heat Transfer Coefficients}

A global heat transfer coefficient is calculated from the measured transient temperature profiles in packed beds. The bed is heated by a hot outer wall until the temperature becomes uniform and equal to that of the bed wall. At time zero, the gas flow is switched to cold air. The wall temperature is kept at the initial temperature of the bed. An experiment is terminated when a steady-state profile is attained. 
large bed

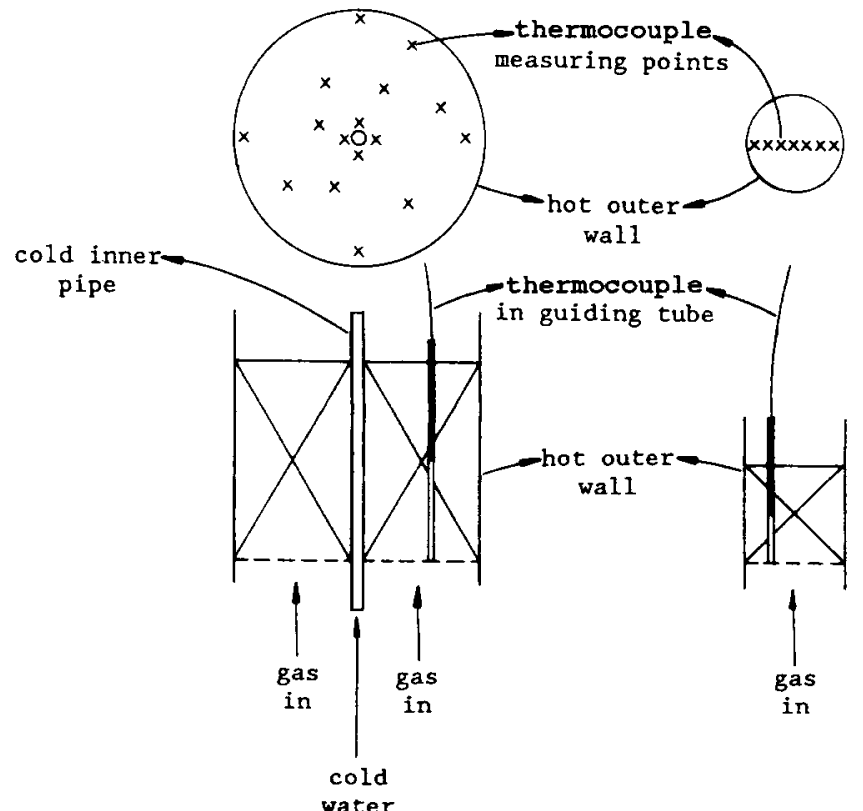

Fig. 1. Experimental set-ups.

The temperature profiles were measured in two packed beds: one large $50 \mathrm{~cm}$ in diameter and $40 \mathrm{~cm}$ high and a small one $22 \mathrm{~cm}$ in diameter and $20 \mathrm{~cm}$ high, see Fig. 1. In the large bed, superficial gas velocities of only up to $15 \mathrm{~cm} / \mathrm{s}$ could be reached; in the small one, superficial gas velocities of up to $3 \mathrm{~m} / \mathrm{s}$ were obtained. Both beds were packed with industrial catalyst pellets, see Fig. 2.

A narrow pipe $20 \mathrm{~mm}$ in outer diameter was installed along the centre axis of the large bed. Cold water flowed through this pipe, allowing us to examine the effect of the wall curvature on its heat transfer coefficient, which will not be discussed here.

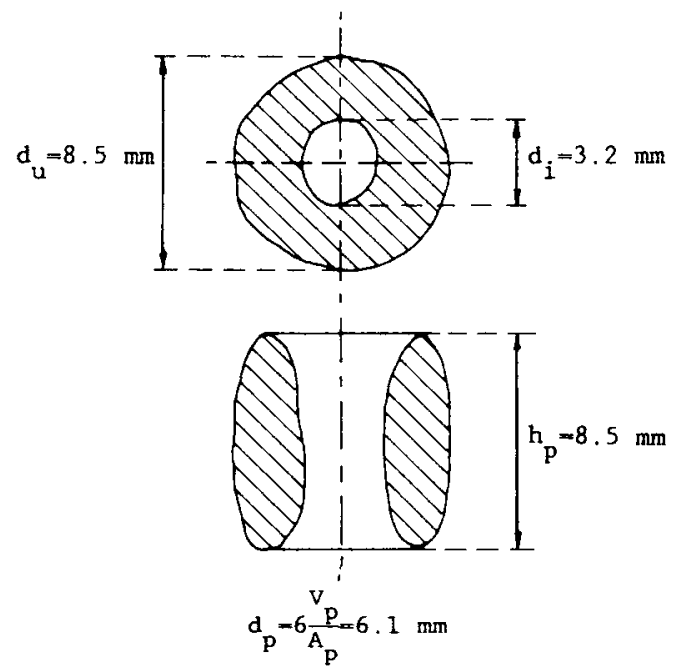

Fig. 2. Geometry of catalyst pellet.
$\mathrm{Nu}$ values were obtained by fitting temperature profiles to the model discussed in the following. It is assumed that accumulation of heat in the gas phase can be neglected. Furthermore, axial dispersion of heat was negligible for the described set-ups, see Wijngaarden [9]. Hence, a heat balance for an infinitesimally small ring in the packed bed yields ${ }^{1)}$ :

$\frac{\partial \theta_{\mathrm{g}}}{\partial \omega}-\frac{1}{\mathrm{Pe}^{\ominus}} \frac{1}{\varrho} \frac{\partial}{\partial \varrho}\left(\varrho \frac{\partial \theta_{\mathrm{g}}}{\partial \varrho}\right)+\mathrm{St}^{\ominus}\left(\theta_{\mathrm{g}}-\theta_{\mathrm{p}}\right)=0$,

$\mathrm{St}^{\ominus}\left(\theta_{\mathrm{g}}-\theta_{\mathrm{p}}\right)-\frac{\partial \theta_{\mathrm{k}}}{\partial \tau}=0$

subject to the initial conditions:

$\omega=0 \rightarrow \theta_{\mathrm{g}}=\theta_{\text {in }}$,

$\tau=0 \rightarrow \theta_{\mathrm{p}}=\theta_{\mathrm{b}}$,

and the boundary conditions:

$\varrho=l \rightarrow \frac{\partial \theta_{\mathrm{g}}}{\partial \varrho}=\mathrm{Bi}_{\mathrm{c}}^{\ominus} \theta_{\mathrm{g}}$,

$\varrho=1 \rightarrow \frac{\partial \theta_{\mathrm{g}}}{\partial \varrho}=\mathrm{Bi}_{\mathrm{h}}^{\ominus}\left(1-\theta_{\mathrm{g}}\right)$

Definitions of the dimensionless numbers can be found in the list of symbols.

Eqs (1) to (6) can be solved to yield the formulae listed in the appendix. The dimensionless groups $\mathrm{Pe}^{\ominus}, \mathrm{Bi}_{\mathrm{h}}^{\ominus}, \mathrm{Bi}_{\mathrm{c}}^{\ominus}$ and $\mathrm{St}^{\ominus}$ can be regarded as compound parameters. They are products of at least two fundamental groups:

$\mathrm{Pe}^{\ominus}=\frac{\operatorname{Pe} N_{\mathrm{D}}}{4 \Gamma \Lambda}$,

$\mathrm{Bi}_{\mathrm{h}}^{\ominus}=\frac{N_{\mathrm{D}} \mathrm{Bi}_{\mathrm{h}}}{2}$

$\mathrm{Bi}_{\mathrm{c}}^{\ominus}=\frac{N_{\mathrm{D}} \mathrm{Bi}_{\mathrm{c}}}{2}$

$\mathrm{St}^{\ominus}=\frac{(1-\varepsilon) N_{\mathrm{D}} \Lambda \mathrm{Nu}}{6 \mathrm{Pe}}$.

The gas temperature profiles in the beds were measured with thermocouples inserted in the bed, see Fig. 1. The measured profiles were fitted to the above global model, using a procedure similar to the direct search method. The truncation error of this method was less than $1 \%$. As a result of this procedure, we obtained best fit values for the compound parameters $\mathrm{Pe}^{\ominus}, \mathrm{Bi}_{\mathrm{h}}^{\ominus}, \mathrm{Bi}_{\mathrm{c}}^{\ominus}$ and $\mathrm{St}^{\ominus}$. This was done

1) List of symbols at the end of the paper. 
for several gas velocities. The superficial gas velocity $v_{0}$ was measured in every experiment; from this, the Peclet number $\mathrm{Pe}=v_{0} d_{\mathrm{p}} / a_{\mathrm{g}}$ could be calculated with $d_{\mathrm{p}}=6.1 \times$ $10^{-3} \mathrm{~m}$ and for air $a_{\mathrm{g}}=4.8 \times 10^{-5} \mathrm{~m}^{2} / \mathrm{s}$. For both packed beds, the porosity $\varepsilon$ was measured by determining the bed volume, the total mass of pellets in the bed and pellet density. Pellet density was found by weighing some pellets and measuring the corresponding upthrust in mercury. The fundamental geometrical groups $N_{\mathrm{D}}, \Lambda$ and $t$ were calculated. The results are listed in Table 1 . Hence, according to Eqs (7)-(10), using the compound parameters $\mathrm{Pe}^{\ominus}, \mathrm{Bi}_{\mathrm{h}}^{\ominus}$, $\mathrm{Bi}_{\mathrm{c}}^{\ominus}$ and $\mathrm{St}{ }^{\ominus}$, the fundamental groups $\Gamma, \mathrm{Bi}_{\mathrm{h}}, \mathrm{Bi}_{\mathrm{c}}$ and $\mathrm{Nu}$ were obtained as functions of $\mathrm{Pe}$ for both packed beds. Only the $\mathrm{Nu}$ values will be discussed here, those of $\Gamma, \mathrm{Bi}_{\mathrm{h}}$ and $\mathrm{Bi}_{\mathrm{c}}$ having been reported by Wijngaarden and Westerterp [10].

\subsection{Local Heat Transfer Coefficients}

Also local values have been determined for $\mathrm{Nu}$. A thermocouple was inserted in a catalyst pellet, see Fig. 3, which measured its temperature. A second thermocouple measured the temperature of the surrounding gas. A rough temperature profile of a specific catalyst pellet and its surrounding gas in the packed bed is shown in Fig. 4. The initial temperatures of both pellet and gas equal the initial bed temperature $T_{\mathrm{b}}$. When the temperature front advancing through the packed bed passes the pellet, the gas temperature starts to fall. Since heat is transferred from pellet to gas, the pellet temperature also decreases. After a certain time, the steadystate temperature $T_{\mathrm{ss}}$ is attained for both pellet and gas. The exact value of the steady-state temperature depends on the pellet's location in the bed.

The Nusselt number of the pellet can be obtained from the pellet heat balance, according to:

$\mathrm{Nu}=\frac{\varrho_{\mathrm{p}} C_{\mathrm{p}, \mathrm{p}} d_{\mathrm{p}}^{2}}{6 \lambda_{\mathrm{g}}} \times\left[T_{\mathrm{p}}\left(t_{1}\right)-T_{\mathrm{p}}\left(t_{2}\right)\right]\left(\int_{t_{1}}^{t_{2}}\left[T_{\mathrm{p}}(t)-T_{\mathrm{g}}(t)\right] \mathrm{\partial} t\right)^{-1}$

where $t_{1}$ and $t_{2}$ may be chosen arbitrarily. The values of $\varrho_{\mathrm{p}}$, $C_{\mathrm{p}, \mathrm{p}}, \lambda_{\mathrm{g}}$ and $d_{\mathrm{p}}$ were obtained experimentally, resulting in $\frac{\varrho_{\mathrm{p}} C_{\mathrm{p}, \mathrm{p}} d_{\mathrm{p}}^{2}}{6 \lambda_{\mathrm{g}}}=275 \mathrm{~s}$. Numerical integration of the measured

transient temperature profiles yielded the local Nusselt numbers.

Table 1. Geometrical parameters of packed beds used in experiments.

\begin{tabular}{lll}
\hline & Large set-up & Small set-up \\
\hline$N_{\mathrm{D}}$ & 83 & 36 \\
$A$ & 0.80 & 0.91 \\
$l$ & 0.040 & 0 \\
$\varepsilon$ & 0.48 & 0.48 \\
\hline
\end{tabular}

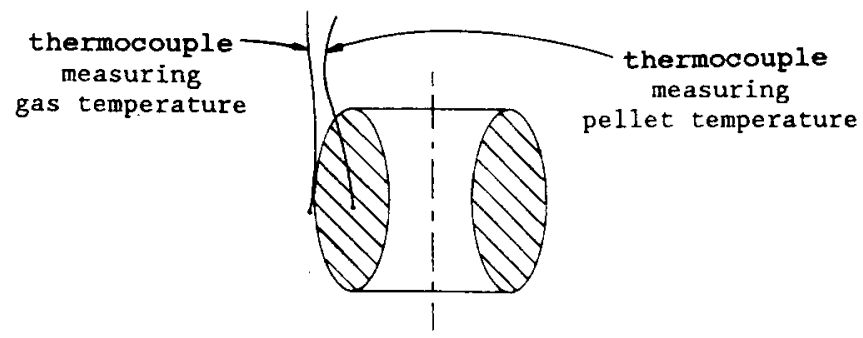

Fig. 3. Measurement of pellet and surrounding gas temperatures for determination of local heat transfer coefficients.

Intraparticle temperature gradients were neglected in the derivation of Eq. (11). This is permissible if the internal heat resistance of the pellet is much lower than the external heat resistance. The particle Biot number:

$$
\mathrm{Bi}_{\mathrm{p}}=\frac{\alpha_{\mathrm{p}} d_{\mathrm{p}}}{\lambda_{\mathrm{p}}}
$$

is a measure of the ratio of these two resistances. Allowing a $10 \%$ error, the following criterion indicates when intraparticle gradients can be neglected:

$\mathrm{Bi}_{\mathrm{p}}<0.1$.

This can also be written as:

$\mathrm{Nu}<0.1 \times \frac{\lambda_{\mathrm{p}}}{\lambda_{\mathrm{g}}}$

Since $\lambda_{\mathrm{g}}=0.037 \mathrm{~W} /(\mathrm{m} \mathrm{K})$ and, for the catalyst $\lambda_{\mathrm{p}}=0.6 \mathrm{~W} /(\mathrm{m} \mathrm{K}), \mathrm{Nu}<2$ will give a contribution of less than $10 \%$.

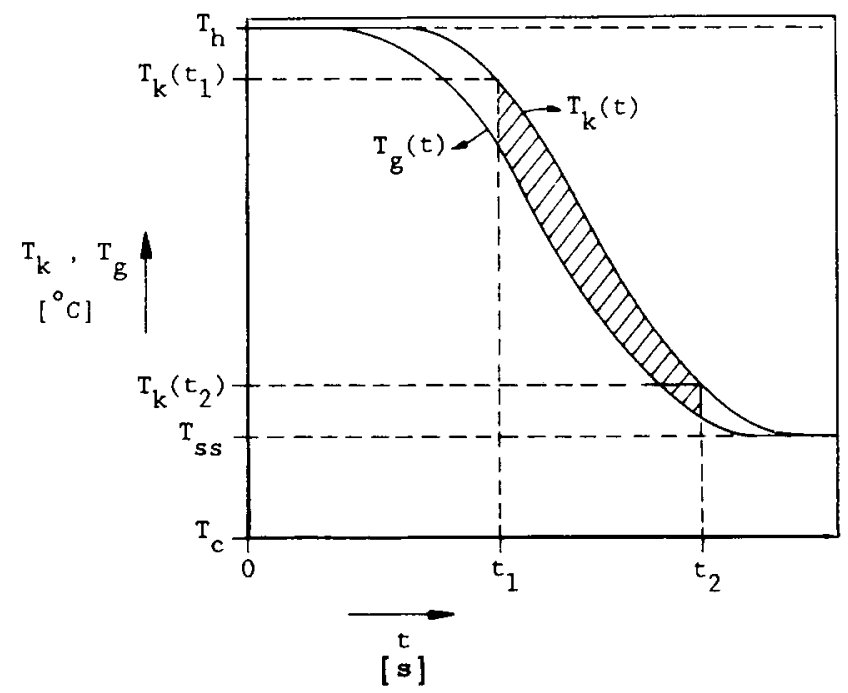

Fig. 4. Pellet and surrounding gas temperature profiles as used for numerical integration to obtain $\mathrm{Nu}$. 


\section{Experimental Results and Discussion}

Fig. 5 presents the obtained global values of $\alpha_{\mathrm{p}}$. In this diagram, $\mathrm{Nu}$ is plotted versus $\mathrm{Pe}$. Two sets of points can be distinguished: one for the large set-up and the other for the small one. General correlations between $\mathrm{Nu}$ and $\mathrm{Pe}$ which would cover the whole range of Peclet numbers, have not been reported. To compare our data with literature, we have shown in Fig. 5 the region of the survey of Kunii and Suzuki [4]. Note that the agreement between our and published results is satisfactory: all points lie within the indicated region.

Finding a best fit of our data to a power law, we obtain:

$\mathrm{Nu}=0.018 \times \mathrm{Pe}^{1.39}, \quad 0.4<\mathrm{Pe}<400$.

This correlation corresponds to the continuous line in Fig. 5. The average deviation of the measured values from those calculated from this correlation, is $9 \%$. We wish to emphasize that two set-ups were employed to obtain this correlation, the catalyst was shaped as Raschig rings and air was used as gas.

As mentioned in the introduction, we also measured the local values for $\mathrm{Nu}$. This was done for two pellets in the large set-up: one pellet in the core and one in the wall region. Both pellets were located halfway up the bed. The results are presented in Fig. 6, where $\mathrm{Nu}$ is plotted versus Pe. Three sets of points are shown: local values in the core and wall region, and the corresponding global values which are derived from the simultaneous fit of the transient profiles.

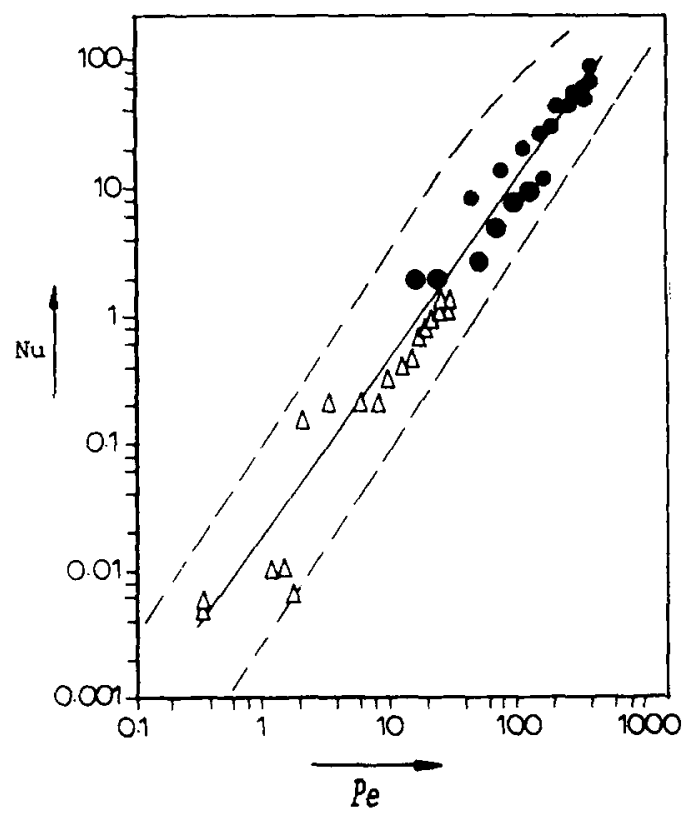

Fig. 5. Global pellet heat transfer coefficient $\mathrm{Nu}$ versus velocity. $\triangle$ Large set-up, $\bullet$ small set up; - - indication of literature data, - Kunii and Suzuki [4], $-\mathrm{Nu}=0.018 \times \mathrm{Pe}^{1.39}$.

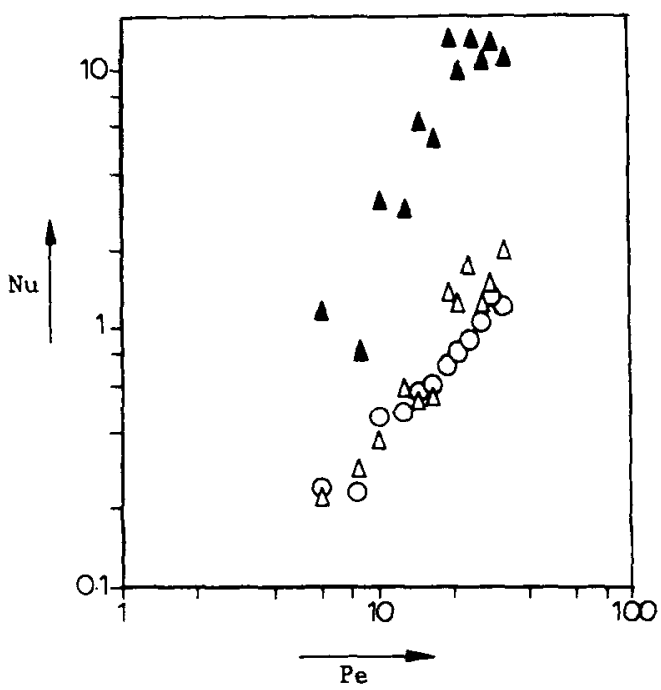

Fig. 6. Global and local pellet heat transfer coefficients $\mathrm{Nu}$ as functions of velocity. Pellets as shown in Fig. 1. Data for large set-up: $\bigcirc$ global values, $\Delta$ local values, wall region, $\Delta$ local values, core region.

It can be seen that there is some scatter of the local values. This is in line with the results of Fedoseev and Shanin [11] who measured local mass transfer coefficients, $k_{\mathrm{g}}$ in a packed bed of stainless steel spheres through which argon was passed with a small amount of uranium hexafluoride. Uranium hexafluoride adsorbed irreversibly on the surface of the stainless steel spheres. By letting argon with $\mathrm{UF}_{6}$ flow through the bed for a given time and then measuring the radioactivity of every individual pellet in the bed, the mass transfer coefficient could be determined for every single particle. Their results indicate that the mass transfer coefficient in the packed bed is distributed. This is illustrated in Fig. 7 where the density distribution for the mass transfer coefficient is approximated by a histogram. This diagram shows the density distribution $f_{\xi}(\xi)$ plotted versus the property $\xi$ defined as:

$\xi=\frac{k_{\mathrm{g}}}{\left\langle k_{\mathrm{g}}\right\rangle}$

where $\left\langle k_{\mathrm{g}}\right\rangle$ is the mass transfer coefficient averaged over all the pellets in the bed. If this is distributed, according to the

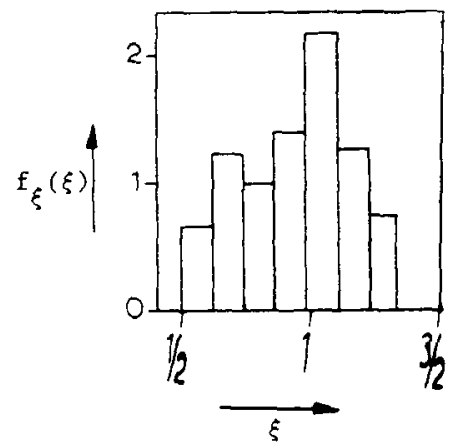
Fig. 7. Density distribution $f_{\xi}(\xi)$ versus $\xi$. (According to Fedoseev and
Shanin [11]). 
Chilton-Colburn analogy, the heat transfer coefficient must be distributed as well. This explains why the relationship between the local $\mathrm{Nu}$ values and Pe in Fig. 6 follows the same trend as the global Nu value, but the points are scattered around the global value.

It was shown that, in the case of the employed pellets, the intraparticle temperature gradients become important for Nusselt numbers above two. Then, the heat resistance due to conduction within the pellet exceeds $10 \%$ of the external heat transfer resistance. This implies that, for a pellet in the core region, we determined too low a value for $\mathrm{Nu}$ since we incorporated the internal heat resistance into the value of $\alpha_{\mathrm{p}}$.

\section{Summary and Conclusions}

Both global and local heat transfer coefficients fall below $\mathrm{Nu}=2$. Therefore, the results presented here contradict the maldistribution hypotheses of Kunii and Suzuki [4] and of Martin [7].

The axial dispersion hypothesis of Gunn and de Souza [5] is also contradicted by our results. As can be seen from Eq. (11), axial dispersion of heat cannot be incorporated in the local values of $\mathrm{Nu}$. It is immaterial what determines the local gas temperature profile; the profile itself is sufficient to calculate $\mathrm{Nu}$. Therefore, axial dispersion will not be incorporated in the local values of $\mathrm{Nu}$. Since these values also fall below 2, and axial dispersion cannot account for this, the explanation of Gunn and de Souza is not sufficient. It could well be, however, that their explanation is valid for a number of results reported in the literature.

Therefore, the hypothesis of Nelson and Galloway [6] appears the most plausible: not only for slurries, as shown by Yagi et al. [8], but also for packed beds.

\section{Acknowlegements}

These investigations are, in part, being supported by the Netherlands' Foundation for Chemical Research SON with financial aid from the Netherlands' Technology Foundation STW.

Received: Sept. 25, 1993 [CET 516]

\section{Symbols used}

$\begin{array}{ll}a_{\mathrm{g}} & {\left[\mathrm{m}^{2} / \mathrm{s}\right]} \\ A_{\mathrm{p}} & {\left[\mathrm{m}^{2}\right]} \\ \mathrm{Bi}_{\mathrm{h}} & {[-]} \\ \mathrm{Bi}_{\mathrm{c}} & {[-]} \\ \mathrm{Bi}_{\mathrm{c}}^{\ominus} & {[-]} \\ \mathrm{Bi}_{\mathrm{h}}^{\ominus} & {[-]} \\ C_{\mathrm{p}, \mathrm{g}} & {[\mathrm{J} /(\mathrm{kg} \mathrm{K})]} \\ C_{\mathrm{p}, \mathrm{p}} & {[\mathrm{J} /(\mathrm{kg} \mathrm{K})]}\end{array}$
Biot number based on particle diamete

$\left(\alpha_{\mathrm{w}, \mathrm{h}} d_{\mathrm{p}} / \lambda_{\mathrm{eff}}\right)$

Biot number based on particle diameter

$\left(\alpha_{\mathrm{w}, \mathrm{c}} d_{\mathrm{p}} / \lambda_{\mathrm{eff}}\right)$

modified Biot number at cold wall $\left(\alpha_{\mathrm{w}, \mathrm{c}} R_{\mathrm{u}} / \lambda_{\text {eff }}\right)$ modified Biot number at hot wall

$\left(\alpha_{\mathrm{w}, \mathrm{h}} R_{\mathrm{u}} / \lambda_{\text {eff }}\right)$

$\left(\alpha_{\mathrm{w}, \mathrm{h}} R_{\mathrm{u}} / \lambda_{\text {eff }}\right)$
specific heat capacity of gas

specific heat capacity of catalyst

$\begin{array}{ll}d_{\mathrm{p}} & {[\mathrm{m}]} \\ f_{\xi}(\xi) & {[-]} \\ k_{\mathrm{g}} & {[\mathrm{m} / \mathrm{s}]} \\ & \\ \left\langle k_{\mathrm{g}}\right\rangle & {[\mathrm{m} / \mathrm{s}]} \\ & \\ L_{\mathrm{t}} & {[\mathrm{m}]} \\ \mathrm{Nu} & {[-]} \\ N_{\mathrm{D}} & {[-]} \\ \mathrm{Pe} & {[-]} \\ \mathrm{Pr} & {[-]} \\ \mathrm{Pe} & {[-]} \\ & \\ r & {[\mathrm{~m}]} \\ \mathrm{Re} & {[-]} \\ R_{\mathrm{i}} & {[\mathrm{m}]} \\ \mathrm{R}_{\mathrm{u}} & {[\mathrm{m}]} \\ \mathrm{St} & {[-]}\end{array}$

\begin{tabular}{|c|c|}
\hline$t$ & [s] \\
\hline$T_{\mathrm{b}}$ & [K] \\
\hline$T_{\mathrm{c}}$ & [K] \\
\hline$T_{\mathrm{g}}$ & {$[\mathrm{K}]$} \\
\hline$T_{\mathrm{h}}^{\mathrm{s}}$ & {$[\mathrm{K}]$} \\
\hline$T_{\text {in }}$ & [K] \\
\hline$T_{\mathrm{p}}$ & [K] \\
\hline$T_{\mathrm{sS}}$ & {$[\mathrm{K}]$} \\
\hline$v_{0}$ & {$[\mathrm{~m} / \mathrm{s}]$} \\
\hline$V_{\mathrm{p}}$ & {$\left[\mathrm{m}^{3}\right]$} \\
\hline$z$ & {$[\mathrm{~m}]$} \\
\hline$\alpha_{\mathrm{p}}$ & {$\left[\mathrm{W} /\left(\mathrm{m}^{2} \mathrm{~K}\right)\right]$} \\
\hline$\alpha_{\mathrm{w}, \mathrm{c}}$ & {$\left[\mathrm{W} /\left(\mathrm{m}^{2} \mathrm{~K}\right)\right]$} \\
\hline$\alpha_{\mathrm{w}, \mathrm{h}}$ & {$\left[\mathrm{W} /\left(\mathrm{m}^{2} \mathrm{~K}\right)\right]$} \\
\hline$\Gamma$ & {$[-]$} \\
\hline$\varepsilon$ & {$[-]$} \\
\hline$\theta_{\mathrm{b}}$ & {$[-]$} \\
\hline$\theta_{\mathrm{g}}$ & {$[-]$} \\
\hline$\theta_{\text {in }}$ & {$[-]$} \\
\hline$\theta_{\mathrm{p}}$ & {$[-]$} \\
\hline$l$ & {$[-]$} \\
\hline$\lambda_{\text {eff }}$ & {$[\mathrm{W} /(\mathrm{m} \mathrm{K})]$} \\
\hline$\lambda_{\mathrm{g}}$ & {$[\mathrm{W} /(\mathrm{m} \mathrm{K})]$} \\
\hline$\lambda_{\mathrm{p}}^{\mathrm{g}}$ & {$[\mathrm{W} /(\mathrm{m} \mathrm{K})]$} \\
\hline$\Lambda$ & {$[-]$} \\
\hline$v_{g}$ & {$\left[\mathrm{~m}^{2} / \mathrm{s}\right]$} \\
\hline$\xi$ & {$[-]$} \\
\hline$\varrho$ & {$[-]$} \\
\hline$\varrho_{\mathrm{g}}$ & {$\left[\mathrm{kg} / \mathrm{m}^{3}\right]$} \\
\hline$\varrho_{\mathrm{p}}$ & {$\left[\mathrm{kg} \mathrm{m}^{3}\right]$} \\
\hline$\tau$ & {$[-]$} \\
\hline$\omega$ & {$[-]$} \\
\hline
\end{tabular}

particle diameter equivalent to a sphere $\left(6 V_{\mathrm{p}} / A_{\mathrm{p}}\right)$ density distribution of $\xi$ mass transfer coefficient of reactant between pellet and gas

average value of $k_{\mathrm{g}}$ for all particles in packed bed

tube length, length of packed bed

particle Nusselt number $\left(\alpha_{\mathrm{p}} d_{\mathrm{p}} / \lambda_{\mathrm{g}}\right)$

number of particles on a diameter $\left(2 R_{\mathrm{u}} / d_{\mathrm{p}}\right)$

particle Peclet number $\left(v_{0} d_{\mathrm{p}} / a_{\mathrm{g}}\right)$

Prandtl number $\left(v_{\mathrm{g}} / a_{\mathrm{g}}\right)$

modified Peclet number based on tube dimen-

sions $\left(\varrho_{\mathrm{g}} C_{\mathrm{p}, \mathrm{g}} v_{0} R_{\mathrm{u}}^{2} /\left(\lambda_{\mathrm{eff}} L_{\mathrm{t}}\right)\right)$

radial coordinate

particle Reynolds number $\left(v_{0} d_{\mathrm{p}} / v_{\mathrm{g}}\right)$

inner radius of packed bed

outer radius of packed bed

modified Stanton number

$\left(6(1-\varepsilon) \alpha_{\mathrm{p}} L_{\mathrm{t}} /\left(\varrho_{\mathrm{p}} C_{\mathrm{p}, \mathrm{g}} v_{0} d_{\mathrm{p}}\right)\right)$

time

initial temperature of catalyst bed

temperature of cold inner tube

gas temperature

temperature of hot outer wall

gas inlet temperature

catalyst temperature

steady-state temperature of a catalyst pellet superficial gas velocity based on empty tube volume of a catalyst pellet

axial coordinate

heat transfer coefficient between particle and gas

heat transfer coefficient at wall of cold inner tube

heat transfer coefficient of hot outer wall dimensionless effective radial thermal conductivity $\left(\lambda_{\text {eff }} / \lambda_{\mathrm{g}}\right)$

porosity, gas hold-up in bed

dimensionless initial temperature of bed

$\left.\left(T_{\mathrm{b}}-T_{\mathrm{c}}\right) /\left(T_{\mathrm{h}}-T_{\mathrm{c}}\right)\right)$

dimensionless gas temperature

$\left(\left(T_{\mathrm{g}}-T_{\mathrm{c}}\right) /\left(T_{\mathrm{h}}-T_{\mathrm{c}}\right)\right)$

dimensionless gas inlet temperature

$\left(\left(T_{\text {in }}-T_{\mathrm{c}}\right) /\left(T_{\mathrm{h}}-T_{\mathrm{c}}\right)\right)$

dimensionless catalyst temperature

$\left(\left(T_{\mathrm{p}}-T_{\mathrm{c}}\right) /\left(T_{\mathrm{h}}-T_{\mathrm{c}}\right)\right)$

ratio of inner to outer radii of packed bed $\left(R_{\mathrm{i}} / R_{\mathrm{u}}\right)$

effective radial thermal conductivity of packed bed

thermal conductivity of gas

thermal conductivity of solid catalyst

aspect ratio $\left(L_{\mathrm{t}} /\left(2 R_{\mathrm{u}}\right)\right)$

kinematic viscosity of gas

$k_{\mathrm{g}} /\left\langle k_{\mathrm{g}}\right\rangle=\alpha_{\mathrm{p}} /\left\langle\alpha_{\mathrm{p}}\right\rangle$

dimensionless radial coordinate $\left(r / R_{\mathrm{u}}\right)$

gas density

density of catalyst particle

dimensionless time

$\left(\left(v_{0} t / L\right) \times\left(\varepsilon \varrho_{\mathrm{g}} C_{\mathrm{p}, \mathrm{g}}\right) /\left((1-\varepsilon) \varrho_{\mathrm{p}} C_{\mathrm{p}, \mathrm{p}}\right)\right)$

dimensionless axial coordinate $\left(z / L_{\mathrm{t}}\right)$

\section{References}

[1] Ranz, W.E., Chem. Eng Prog. 48 (1952) pp. 247- 253.

[2] Gnielinski, V., Chem.-Ing.-Tech. 52 (1980) No. 3, pp. $228-236$. 
[3] Gnielinski, V., Verfahrenstechnik (Mainz) 16 (1982) pp. 36-39.

[4] Kunii, D., Suzuki, M., Int. J. Heat Mass Transfer 10 (1967) pp. $845-852$.

[5] Gunn, D.J., de Souza, J.F.C., Chem. Eng Sci. 29 (1974) pp. $1363-1371$.

[6] Nelson, P.A., Galloway, T.R., Chem. Eng Sci. 30 (1975) pp. $1-6$.

[7] Martin, H., Chem. Eng Sci. 33 (1978) pp. 913-919.

[8] Yagi, H., Motouchi, T., Hikita, H., Ind. Eng Chem., Process Des. Dev. 23 (1984) pp. $145-150$.

[9] Wijngaarden, R.J., Thesis, Univ. Twente, The Netherlands, 1989.

[10] Wijngaarden, R. J., Westerterp, K.R., Chem. Eng Sci. 48 (1993) pp. $1273-1280$.

[11] Fedoseev, V. N., Shanin, O. I., Inzh.-Fiz. Zh. 51 (1986) No. 2, pp. $194-198$.

\section{Appendix}

Partial differential Eqs (1) and (2), subject to the initial conditions (3) and (4) and the boundary conditions (5) and (6), were solved via the Laplace transform of this set with respect to $\tau$ and $\omega$. Inversion from the Laplace domain was effected with the aid of a complex inversion formula. The result is:

$$
\begin{aligned}
& \theta_{\mathrm{g}}=\frac{1 / \imath-\mathrm{Bi}_{\mathrm{c}}^{\ominus} \ln (\varrho / l)}{1 / l-\mathrm{Bi}_{\mathrm{c}}^{\ominus} \ln t+\left(\mathrm{Bi}_{\mathrm{c}}^{\odot} / \mathrm{Bi}_{\mathrm{h}}^{\ominus}\right)}+ \\
& +\sum_{i=1}^{\infty}\left\{\frac { 2 } { \lambda _ { \mathrm { i } } } \left[\left(\frac{\Theta\left(\lambda_{\mathrm{i}}\right)-\theta_{\mathrm{b}} \Xi\left(\lambda_{\mathrm{i}}\right)}{\Phi\left(\lambda_{\mathrm{i}}\right)}\right) \times\left(\frac{1}{1+\eta_{\mathrm{i}}}\right) \times\right.\right. \\
& \times\left[\left(1-\frac{\mathrm{e}^{-\left(1+\eta_{\mathrm{i}}\right)}}{1+\eta_{\mathrm{i}}} \times \int_{0}^{\mathrm{St}^{\ominus_{\tau}}} I_{0}\left(2 \sqrt{\mathrm{St}^{\ominus}} \overline{\omega u)} \mathrm{e}^{-u /\left(1+\eta_{\mathrm{i}}\right)} \mathrm{d} u\right) \times\right.\right.
\end{aligned}
$$

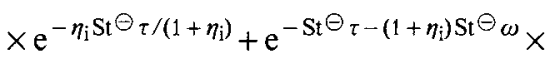

$$
\begin{aligned}
& \left.\times I_{0}\left(2 \mathrm{St}^{\ominus} \sqrt{\omega \tau}\right)\right]+\left(\frac{\Theta\left(\lambda_{\mathrm{i}}\right)-\dot{\theta_{0} \Xi}\left(\lambda_{\mathrm{i}}\right)}{\Phi\left(\lambda_{\mathrm{i}}\right)}\right) \times \\
& \times\left(\mathrm{e}^{-\left(1+\eta_{\mathrm{i}} \mathrm{St} \Theta_{\omega}\right)} \times \int_{0}^{\mathrm{St}_{\mathrm{\tau}}^{\prime}} I_{0}\left(2 \sqrt{\mathrm{St}^{\Theta} \omega u}\right) \mathrm{e}^{-u} \mathrm{\partial} u-\right. \\
& \left.\left.\left.-\mathrm{e}^{-\mathrm{St} \Theta_{\tau-\left(1+\eta_{\mathrm{i}}\right) \mathrm{St} \Theta \omega}} \times I_{0}\left(2 \mathrm{St} \ominus^{\omega \tau}\right)\right)\right]\right\}, \\
& \theta_{\mathrm{p}}=\frac{1 / l-\mathrm{Bi}_{\mathrm{c}}^{\ominus} \ln (\varrho / l)}{1 / l-\mathrm{Bi}_{\mathrm{c}}^{\ominus} \ln t+\left(\mathrm{Bi}_{\mathrm{c}}^{\ominus} / \mathrm{Bi}_{\mathrm{h}}^{\ominus}\right)}+\mathrm{e}^{-\mathrm{St}^{\ominus} t} \times \\
& \times\left(\theta_{\mathrm{b}}-\frac{1+\mathrm{Bi}_{\mathrm{c}}^{\ominus} \ln (\varrho / l)}{1 / l-\ln l+\left(\mathrm{Bi}_{\mathrm{c}}^{\ominus} / \mathrm{Bi}_{\mathrm{h}}^{\ominus}\right)}\right)+
\end{aligned}
$$

$$
\begin{aligned}
& +\sum_{i=1}^{\infty}\left\{\frac { 2 } { \lambda _ { \mathrm { i } } } \left[\left(\frac{\Theta\left(\lambda_{\mathrm{i}}\right)-\theta_{\mathrm{b}} \Xi\left(\lambda_{\mathrm{i}}\right)}{\Phi\left(\lambda_{\mathrm{i}}\right)}\right) \times\left[\mathrm{e}^{-\eta_{\mathrm{i}} \mathrm{St} \Theta_{\tau} /\left(1+\eta_{\mathrm{i}}\right)} \times\right.\right.\right. \\
& \times\left(1-\frac{\mathrm{e}^{-\left(1+\eta_{\mathrm{i}}\right)}}{1+\eta_{\mathrm{i}}} \times \int_{0}^{\mathrm{St} \ominus_{\tau}} I_{0}\left(2 \sqrt{\left.\mathrm{St}^{\ominus} \omega u\right)} \mathrm{e}^{-u /\left(1+\eta_{\mathrm{i}}\right)} \partial u\right)-\right. \\
& \left.-\mathrm{e}^{-\mathrm{St} \ominus_{\tau}}\right]+\left(\frac{\Theta\left(\lambda_{\mathrm{i}}\right)-\theta_{0} \Xi\left(\lambda_{\mathrm{i}}\right)}{\Phi\left(\lambda_{\mathrm{i}}\right)}\right) \times \mathrm{e}^{-\left(1+\eta_{\mathrm{i}} \mathrm{St} \Theta \omega\right)} \times \\
& \left.\left.\times \int_{0}^{\mathrm{St} \ominus_{\tau}} I_{0}(2 \sqrt{\mathrm{St} \Theta \omega u}) \mathrm{e}^{-u} \partial u\right]\right\}
\end{aligned}
$$

with

$$
\begin{aligned}
& \eta_{\mathrm{i}}=\frac{\lambda_{\mathrm{i}}^{2}}{\mathrm{Pe}^{\ominus} \mathrm{St}^{\ominus}}, \\
& \Theta(\lambda)=P_{0}(\lambda \varrho, \lambda l)-\frac{\lambda}{\mathrm{Bi}_{\mathrm{c}}^{\ominus}} Q_{0}(\lambda \varrho, \lambda l), \\
& \Xi(\lambda)= P_{0}(\lambda, \lambda \varrho)+P_{0}(\lambda \varrho, \lambda l)-\frac{\lambda}{\mathrm{Bi}_{\mathrm{c}}^{\ominus}} Q_{0}(\lambda \varrho, \lambda l)- \\
&-\frac{\lambda}{\mathrm{Bi}_{\mathrm{h}}^{\ominus}} Q_{0}(\lambda \varrho, \lambda), \\
& \Phi(\lambda)= \lambda P_{0}(\lambda, \lambda l)\left(\frac{l}{\mathrm{Bi}_{\mathrm{c}}^{\ominus}}-\frac{1}{\mathrm{Bi}_{\mathrm{h}}^{\ominus}}\right)+ \\
&+\lambda P_{1}(\lambda, \lambda l)\left(\frac{l}{\mathrm{Bi}_{\mathrm{h}}^{\ominus}}-\frac{1}{\mathrm{Bi}_{\mathrm{c}}^{\ominus}}\right)+ \\
&+Q_{0}(\lambda, \lambda l)\left(l+\frac{\lambda^{2}}{\mathrm{Bi}_{\mathrm{c}}^{\ominus} \mathrm{Bi}_{\mathrm{h}}^{\ominus}}\right)- \\
&-Q_{0}(\lambda l, \lambda)\left(1+\frac{\lambda^{2} l}{\mathrm{Bi}_{\mathrm{c}}^{\ominus} \mathrm{Bi}_{\mathrm{h}}^{\ominus}}\right)
\end{aligned}
$$

and $\lambda_{1}$ the $i^{\text {th }}$ root of the equation:

$$
\begin{gathered}
P_{0}(\lambda, \lambda l)-\frac{\lambda}{\mathrm{Bi}_{\mathrm{h}}^{\ominus}} Q_{0}(\lambda l, \lambda)-\frac{\lambda}{\mathrm{Bi}_{\mathrm{c}}^{\ominus}} Q_{0}(\lambda, \lambda l)- \\
-\frac{\lambda^{2}}{\mathrm{Bi}_{\mathrm{c}}^{\ominus} \mathrm{Bi}_{\mathrm{h}}^{\ominus}} P_{1}(\lambda, \lambda l)=0 .
\end{gathered}
$$

$P_{0}, P_{1}$ and $Q_{0}$ are the following cross-products:

$$
P_{0}(a, b)=J_{0}(a) Y_{0}(b)-Y_{0}(a) J_{0}(b),
$$


$P_{1}(a, b)=J_{1}(a) Y_{1}(b)-Y_{1}(a) J_{1}(b)$,

$Q_{0}(a, b)=-J_{0}(a) Y_{1}(b)+Y_{0}(a) J_{1}(b)$,

(25) of the first kind, respectively, and $Y_{0}, Y_{1}$ the zeroth and first order Bessel functions of the second kind, respectively.

(26) $I_{0}$ is the zeroth order modified Bessel function of the first kind. $\varrho, \omega, \tau, l, \theta_{\mathrm{g}}, \theta_{\mathrm{k}}, \theta_{0}, \theta_{\mathrm{b}}, \mathrm{St}^{\ominus}, \mathrm{Pe}^{\ominus}, \mathrm{Bi}_{\mathrm{c}}^{\ominus}$ and $\mathrm{Bi}_{\mathrm{h}}^{\ominus}$ are where $J_{0}, J_{1}$ are the zeroth and first order Bessel functions listed as symbols used. 